\title{
Computer assisted echocardiographic assessment of left ventricular function before and after anatomical correction of transposition of the great arteries
}

\author{
F W ARENSMAN, * R RADLEY-SMITH, $\dagger$ L GRIEVE, $\dagger$ D G GIBSON, \\ M H YACOUB $†$ \\ From $\nmid$ Harefield Hospital, Harefield, Middlesex; $\ddagger$ Brompton Hospital, London; and ${ }^{\star M e d i c a l ~ C o l l e g e ~ o f ~}$ \\ Georgia, Augusta, Georgia, USA
}

SUMMARY Left ventricular function before and after anatomical correction of transposition of the great arteries was assessed by computer assisted analysis of 78 echocardiographs from 27 patients obtained one year before to five years after operation. Sixteen patients had simple transposition, and 11 had complex transposition with additional large ventricular septal defect. Immediately after correction mean shortening fraction fell from $46(9) \%$ to $33(8) \%$. There was a corresponding drop in normalised peak shortening rate from $5 \cdot 4(3.7)$ to $3.3(1 \cdot 1) \mathrm{s}^{-1}$ and normal septal motion was usually absent. Systolic shortening fraction increased with time after correction and left ventricular end diastolic diameter increased appropriately for age. The preoperative rate of free wall thickening was significantly higher in simple $\left(5 \cdot 6(2 \cdot 8) \mathrm{s}^{-1}\right)$ and complex transposition $\left(4.5(1.8) \mathrm{s}^{-1}\right)$ than in controls $\left(2.9(0.8) \mathrm{s}^{-1}\right)$. After operation these values remained high in both the short and long term. Thus, computer assisted analysis of left ventricular dimensions and their rates of change before and after anatomical correction showed only slight postoperative changes which tended to become normal with time. Septal motion was commonly absent after operation. This was associated with an increase in the rate of posterior wall thickening that suggested normal ventricular function associated with an altered contraction pattern.

Computer assisted echocardiographic analysis may be helpful in the long term assessment of ventricular function after operation for various heart abnormalities.

When compared with intra-atrial procedures ${ }^{12}$ for transposition of the great arteries, anatomical correction offers the potential advantage of converting the left ventricle to a systemic pump. ${ }^{3}$ There are few data on left ventricular function immediately after or long after anatomical repair, and a safe, repeatable, preferably non-invasive, method of assessment is required. Computer assisted echocardiographic analysis is a sensitive reliable method of assessing ventricular function in both children ${ }^{4}$ and adults, ${ }^{5}$ and we have used it to evaluate patients before and after anatomical correction of transposition of the great arteries.

Requests for reprints to Dr F W Arensman, Department of Pediatrics, Section of Pediatric Cardiology, Medical College of Georgia, Augusta, GA 30912, USA.

Accepted for publication 14 September 1985

\section{Patients and methods}

STUDY GROUPS

We studied 27 patients who underwent anatomical correction of transposition of the great arteries. These children comprise $75 \%$ of all those who underwent this procedure at Harefield Hospital from October 1976 to January 1982. Most of the remaining children live abroad and were unavailable for re-examination. There was no other known bias in patient selection. Sixteen children $(59 \%)$ had simple transposition without other important defects and 11 $(41 \%)$ had additional lesions-a ventricular septal defect in 10 and an aortopulmonary window in one. All patients with simple transposition underwent either pulmonary artery banding or pulmonary artery banding combined with a Blalock-Taussig shunt ${ }^{6}$ from 12 to 2.5 months before anatomical cor- 
rection. Age at definitive repair ranged from 1 to 120 months (mean 14.6 months). Operative technique and perioperative management have been reported elsewhere.?

Preoperative echocardiograms were recorded from eight months to one day before anatomical correction, early postoperative echocardiograms from one day to six months after repair, and late postoperative studies from six months to five years after repair.

The control population consisted of 36 healthy children aged 18 to 97 months (mean 71.8 ). Some of these data have been reported in a previous paper. ${ }^{4}$

\section{MODE ECHOCARDIOGRAMS}

Echocardiograms were obtained in the standard manner ${ }^{8}$ with a Smith-Kline Echoline machine interfaced with a Cambridge 70-A Multichannel recorder. An appropriate transducer was used with the patients in supine or left lateral position. Paper speed was usually $75 \mathrm{~mm}$ per second and a simultaneous electrocardiogram was always recorded. The transverse dimension of the left ventricle was always measured at the level of the mitral valve tips. An echocardiogram was acceptable for inclusion in the study when the right and left septal surfaces, left ventricular free wall endocardium, and left ventricular free wall epicardium were simultaneously displayed. The leading edge of each structure was traced in at least two and usually in five beats and the results were averaged. No premature or postextrasystolic beats were included. There were 78 acceptable echocardiograms among 232 that were performed. Most of the original echocardiograms were unacceptable for digitisation because all four surfaces were not simultaneously imaged.

\section{DIGITISATION}

Tracings were digitised by the method of Gibson and Brown. ${ }^{9}$ End diastolic dimension was measured synchronously with the electrocardiographic $Q$ wave. End systolic dimension was measured at the time of peak anterior motion of the posterior wall endocardium. This method differs from that recommended by the American Society of Echocardiography ${ }^{10}$ because a method based on maximum posterior septal motion is inapplicable in a population with abnormal septal motion.

We analysed plots of left ventricular dimension, rates of change of dimension, normalised rates of change of dimension, as well as posterior wall and septal thickness and the rate of change of the thickness of the posterior wall (Fig. 1). From these measurements we obtained peak rates of change of dimension and wall thickness in both systole and diastole.
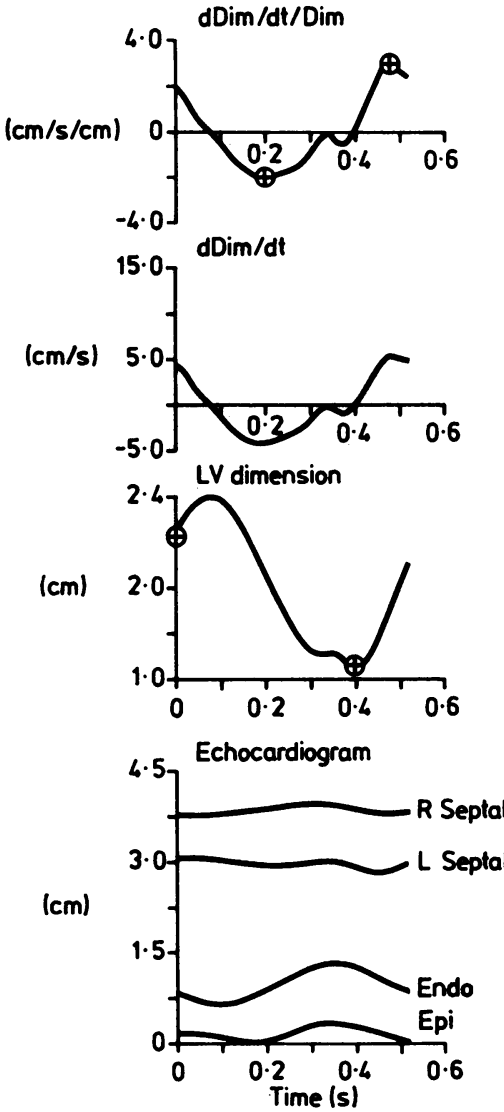

Fig. 1 Typical computer printout of digitised beat showing echocardiogram, continuous left ventricular ( $L V)$ dimension with time, change in dimension with change in time, normalised change in dimension with change in time. Peak normalised rate of emptying and rate of filling are indicated by $\oplus$.

\section{STATISTICAL ANALYSIS}

Data were compared as individual data points as well as means (1 SD). We used a non-paired $t$ test for comparision between groups. A p value $<0.05$ was regarded as significant.

\section{Results}

LEFT VENTRICULAR END DIASTOLIC DIMENSION Preoperative end diastolic dimension was smaller in patients with simple transposition $(1.9(0.4) \mathrm{cm})$ than in those with complex transposition $(3.0(0.4) \mathrm{cm}$ ) $(\mathrm{p}<0.01)$ (Fig. 2). Measurements from short term postoperative studies were not significantly different in simple and complex transposition. The mean left end diastolic dimension was $2.3(0.8) \mathrm{cm}$ in simple 


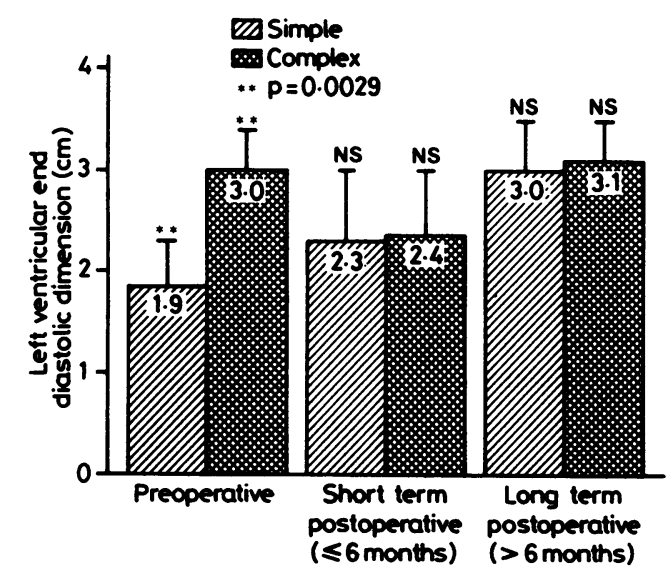

Fig. 2 Left ventricular end diastolic dimension (LVEDD) before and after correction of transposition. Preoperative LVEDD was significantly greater in children with complex transposition. Postoperative values were not significantly different in either short or long term follow up.

transposition and $2 \cdot 4(0 \cdot 6) \mathrm{cm}$ in complex transposition. Similarly there was no significant difference between the groups more than six months after repair-simple transposition $3.0(0 \cdot 6) \mathrm{cm}$ and complex transposition $3 \cdot 1(0.5) \mathrm{cm}$. After anatomical correction there was growth of the left ventricle with time in all patients (Fig. 3).

\section{SHORTENING FRACTION}

The preoperative shortening fraction was higher in patients with simple transposition $(51(19) \%)$ than in those with complex transposition ( $43(7) \%)$, but not significantly (Fig. 4). The shortening fraction before operation in both groups was significantly higher than in the controls $(34(5) \%)(p=0.0001$ for simple

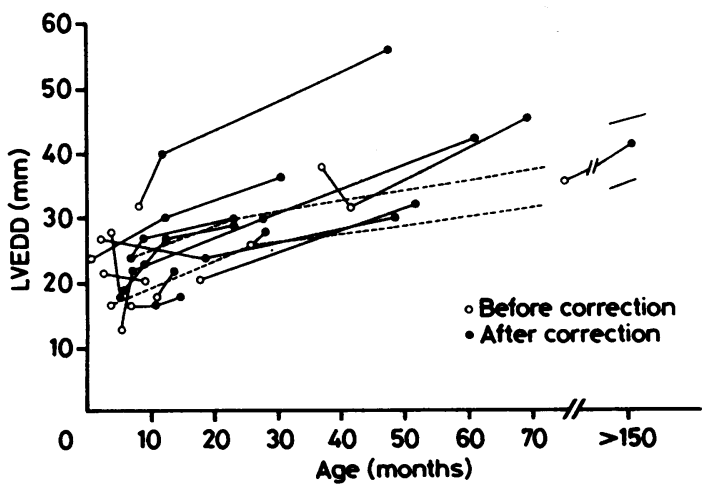

Fig. 3 Left ventricular end diastolic dimension ( $L V E D D$ ) ( $\mathrm{mm}$ ) in 14 patients in relation to age in months. $95 \%$ confidence limits of the line of regression are shown. ${ }^{11}$
Arensman, Radley-Smith, Grieve, Gibson, Yacoub

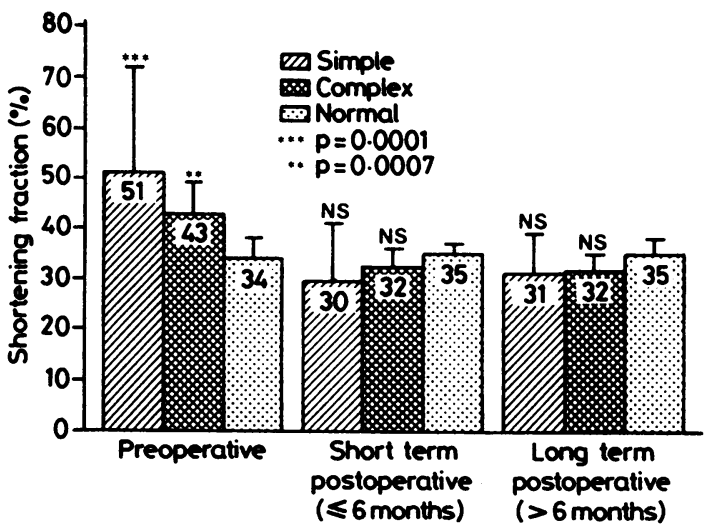

Fig. 4 Shortening fraction before and after repair. The shortening fraction before operation was significantly higher $\mathrm{O}$ in patients with simple and complex transposition than in controls. After operation there was a decrease in shortening fraction and postoperative values are not significantly different from that in controls.

transposition and $p=0.007$ for complex transposition).

The shortening fraction fell immediately after operation to $30(11) \%$ in simple and $32(4) \%$ ) ino complex transposition. Neither value was signficantly different from that in controls $(35(2) \%)$. In the long term the shortening fraction remainedo virtually unchanged $(31(8) \%$ in simple transposition 0 and $32(4) \%$ in complex tranpositions). Neither $\vec{O}$ value was significantly different from that in controls 3 $(35(3) \%)$.

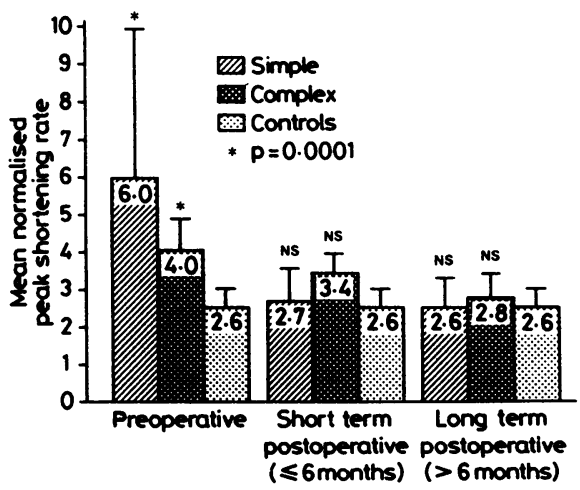

Fig. 5 Normalised peak rate of shortening before and after $\stackrel{\mathbb{S}}{-}$ repair. Before operation patients with simple or complex transposition had significantly greater normalised peak shortening rates than controls. After operation the normalised peak rate of shortening was not significantly different from that in controls. 


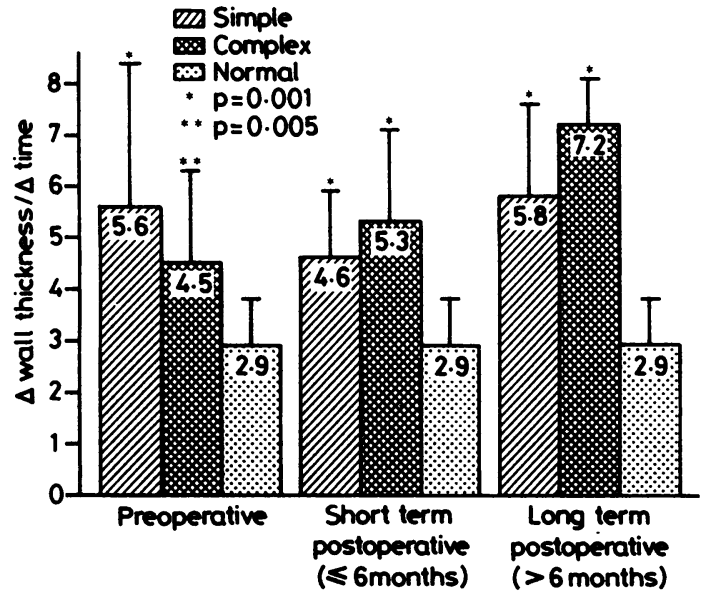

Fig. 6 Free wall thickening before and after operation. At all stages the transposition groups have significantly higher rates of free wall thickening than the controls. These differences tend to increase with time.

NORMALISED PEAK RATES OF SHORTENING Before operation peak normalised rates of shortening in patients with both simple and complex transposition were significantly greater than that in controls: $6.0(3.9) \mathrm{s}^{-1}$ in simple and $4.0(0.9) \mathrm{s}^{-1}$ in complex and $2.6(0.5) \mathrm{s}^{-1}$ in controls (for both simple and complex $p=0.0001$ ) (Fig. 5). In the short term postoperative period both patient groups had reduced peak shortening rates $\left(2 \cdot 7(0.9) \mathrm{s}^{-1}\right.$ in simple and $3.4(0.5) \mathrm{s}^{-1}$ in complex transposition). They were not significantly different from the rate in controls. Postoperative values in the long term were essentially unchanged $\left(2.6(0.8) \mathrm{s}^{-1}\right.$ simple and $2.8(0.5) \mathrm{s}^{-1}$ complex) and they were not significantly different from that in controls $(2.6(0.5)$ $\left.s^{-1}\right)$.

\section{FREE WALL THICKENING}

The postoperative rate of free wall thickening was significantly greater in patients with transposition than in controls (Fig. 6). These differences tended to increase with time after operation. The mean values for peak thickening rate before operation were $5.6(2 \cdot 8) \mathrm{s}^{-1}$ in simple transposition and $4.5(1.8) \mathrm{s}^{-1}$ in complex transposition. They were significantly greater than that in controls $(p=0.001$ simple), $(\mathrm{p}=0.005$ complex). These differences persisted in both groups soon after operation (simple $4.6(1 \cdot 2)$ $\mathrm{s}^{-1}$, complex $\left.5.3(1.8) \mathrm{s}^{-1}\right)$; controls $2.9(0.8) \mathrm{s}^{-1}$ ( $p=0.001$ for both comparisons). In the long term postoperative values in both patient groups remained raised $\left(5 \cdot 8(1 \cdot 7) \mathrm{s}^{-1}\right.$ for simple transposition, $7 \cdot 2(1 \cdot 0) \mathrm{s}^{-1}$ for complex tranposition, and $2 \cdot 9(0 \cdot 8)$ $s^{-1}$ for controls) ( $p=0.001$ for both simple and complex). These values were not significantly different from the immediate postoperative values. Patients with high values in the short term tended to have increased rate of free wall thickening in the long term studies as well $(p=0.042)$.

\section{SEPTAL MOTION}

Septal motion was satisfactorily displayed in 23 patients before anatomical correction. It was normal in $21(93 \%)$, absent in one (4\%), and reversed in one $(4 \%)$. Shortly after operation only four $(17 \%)$ of 24 patients had normal septal motion. It was absent in $14(58 \%)$ patients and reversed in six (25\%). More than six months after anatomical correction 12 ( $48 \%$ ) of 25 children had absent septal motion, while in five $(20 \%)$ of 25 the direction was normal but amplitude was reduced. In eight (32\%) of 25 normal direction and amplitude of septal motion had returned.

\section{Discussion}

After Mustard ${ }^{1}$ and Senning ${ }^{2}$ procedures both clinical and subclinical systemic (right) ventricular dysfunction are known to occur. ${ }^{12-14}$ The major potential advantage of anatomical correction of transposition of the great arteries is the conversion of the left ventricle to a systemic pump. The long term success of anatomical correction is, therefore, dependent on adequate left ventricular function. It is not clear if completely normal function can be expected. Even after repair of relatively simple lesions, such as isolated ventricular septal defect, left ventricular dysfunction has been reported. ${ }^{1516}$ Newer operative techniques and early surgical repair, however, seem to have improved postoperative ventricular size and function. ${ }^{17}$ Transient left ventricular failure has been reported immediately after anatomical correction of transposition of the great arteries. ${ }^{1819}$ In long term survivors, however, left ventricular ejection fraction and end diastolic pressure are reported to be normal. ${ }^{20}$ The left ventricular contractile state was examined after operation in a small series of children from Harefield. In every child who underwent repair before the age of one the left ventricular end diastolic dimension and wall stress-shortening were normal. ${ }^{21}$

Echocardiographic findings have been described before and after arterial switch ${ }^{22}$ and Mustard procedure in children for transposition of the great arteries. ${ }^{23}$ Septal motion was judged to be abnormal in almost all children before and after Mustard's operation. ${ }^{23}$ When anatomical correction or the arterial switch included repair of a ventricular septal defect, septal motion was always abnormal. ${ }^{22}$ After 
an intra-atrial repair, septal motion may be incorporated into emptying of the high pressure right ventricle. Absent or paradoxical septal motion is common after open heart procedures and should not be equated with intrinsic ventricular dysfunction. ${ }^{24}$ In our current series only $4 \%$ of children had normal septal motion immediately after operation. More than six months after repair, however, $32 \%$ of the patients had normal septal motion.

Before operation the left ventricular dimension was larger when a ventricular septal defect was present (Fig. 2). This is probably the result of shunting from the systemic right ventricle to the pulmonary left ventricle. In a group studied in Toronto left ventricular size vaired considerably before definitive correction. ${ }^{22}$

In our series, there were no significant differences in left ventricular size between patients with simple transposition or those with complex transposition, either immediately or more than six months after operation. In addition left ventricular size increased appropriately with advancing age (Fig. 4). We know of no other series in which the growth of the left ventricle has been evaluated after anatomical correction.

Before repair the shortening fraction was higher than normal in both those with simple and those with complex transposition (Fig. 5). Despite adequate pulmonary artery banding in patients with simple transposition, the left ventricular afterload is probably subsystemic. This may account for the increased shortening fraction. The increased normalised peak shortening rates in the patients before operation could also be explained by reduced left ventricular afterload.

After repair there was a signficant reduction in shortening fraction, but values in those with simple and those with complex transposition were not significantly different from that in controls. Peak shortening rates also fell to normal values immediately after repair and remained normal in long term studies.

Rates of free wall thickening in those with simple and those with complex transposition were significantly greater than normal (Fig. 6). In the preoperative period this increased rate of thickening could be explained on the basis of diminished afterload; that is the left ventricular free wall contracts faster in the face of low afterload. In both short and long term postoperative follow up studies the rate of free wall thickening remained greater than normal and may increase with time. In the presence of flat or diminished septal motion and normal peak rate of shortening, the rate of posterior wall thickening may increase as a compensatory response and produce a normal shortening fraction. There was a close cor- relation between an increase in the long term rate of free wall thickening and high shortening fraction $(p=0.028)$.

These data indicate changes in ventricular wall motion both before and after anatomical correction. The reductions in shortening fraction, in the amplitude of septal motion, and in peak shortening rate in the immediate postoperative period are probably related to the sudden change in ventricular afterload and the effects of open heart surgery itself. Postoperative differences include reduced septal motion and persistence of the increase in rate of thickening of the posterior wall. This latter feature cannot be explained on the basis of overall movement of the heart in space but, taken in conjunction with septal hypokinesis, seems to indicate a pattern of contraction that is altered, but not necessarily impaired since changes in overall cavity size were normal and since the systemic ventricle grows with age. These data are part of a continuing study that may shed further light on this question. Although even more long term results are not yet available, observations as long as five years after correction seem to indicate adequate left ventricular function after correction. We conclude that left ventricular function is maintained after anatomical correction of transposition of the great arteries. We expect that this operation will become more widely accepted as the procedure of choice for selected infants.

We thank Karl Hammermeister for assistance with digitising, David Hughes and Steve Saunders for help with computer programming, and D Naftel, E Blackstone (of the University of Alabama), and Harry Davis for statistical assistance.

F W A was a British-American Research Fellow of the American Heart Association and British Heart Foundation.

\section{References}

1 Mustard WT. Successful two stage correction of transposition of the great vessels. Surgery $1964 ; 55$ : 469-72.

2 Senning A. Surgical correction of transposition of the great vessels. Surgery 1959; 45: 966-80.

3 Yacoub MH. The case for anatomic correction of transposition of the great arteries. $\mathcal{F}$ Thorac Cardiovasc Surg 1979; 78: 3-6.

4 St John Sutton MG, Marier DL, Oldershaw PJ, Sacchetti R, Gibson DG. Effect of age related changes in chamber size, wall thickness, and heart rate on left ventricular function in normal children. Br Heart $\mathcal{f} 1982$ 48: 342-51.

5 Gibson DG, Traill TA, Brown DJ. Changes in left ventricular free wall thickness in patients with ischaemic heart disease. Br Heart $\mathcal{F}$ 1977; 39: 1312-8. 
6 Blalock A, Taussig HB. The surgical treatment of malformations of the heart in which there is pulmonary stenosis or atresia. FAMA 1945; 128: 189-202.

7 Yacoub MH, Radley-Smith R, Hilton CJ. Anatomical correction of complete transposition of the great arteries and ventricular septal defect in infancy. $\mathrm{Br}$ Med $\mathcal{F} 1976$; i: $1112-4$.

8 Biancaniello T, Meyer RA, Wong KY, Sagar C, Kaplan S. Doxorubicin cardiotoxicity in children. $f$ Pediatr 1980; 97: 45-50.

9 Gibson DG, Brown D. Measurement of instantaneous left ventricular dimension and filling in man, using echocardiography. Br Heart $\mathcal{f}$ 1973; 35: 1141-9.

10 Sahn DJ, DeMaria A, Kisslo J, Weyman A. The committee on M-mode standarization of the American Society of Echocardiography recommendations regarding quantitation in $\mathrm{M}$-mode echocardiography: results of a survey of echocardiographic measurements. Circulation 1978; 58: 1072-83.

11 Meyer RA. Table A3: Normal values for children arranged by age, weight and height. Appendix. In: Pediatric echocardiography. Philadelphia: Lea and Febiger, 1977: 293.

12 Nixon JV, Atkins JM, Curry GC, Buja LM, Miller WW. Late right ventricular failure after Mustard operation for transposition of the great arteries. Cathet Cardiovasc Diagn 1978; 4: 175-82.

13 Hagler DJ, Ritter DG, Mair DD, et al. Right and left function after the Mustard procedure in transposition of the great arteries. Am F Cardiol 1979; 44: 276-83.

14 Graham TP. Hemodynamic residua and dequelae following intraatrial repair of transposition of the great arteries: a review. Pediatr Cardiol 1982; 2: 203-13.

15 Feigenbaum H. Interventricular septum. In: Echocardiography. Philadelphia: Lea and Febiger, 1976: 289.

16 Jarmakani JM, Graham TP Jr, Canet RV, Capp MD.
The effect of corrective surgery on left heart volume and mass in children with ventricular septal defect. $A m \mathcal{F}$ Cardiol 1972; 27: 254-8.

17 Cordell D, Graham TP Jr, Atwood GF, Boerth RC, Bovcek RJ, Bender HW. Left heart volume characteristics following ventricular septal defect closure in infancy. Circulation 1976; 54: 294-8.

18 Yacoub MH, Arensman FW, Radley-Smith R, Bernhard A, Lange P, Heintzen P. Results of correction of transposition of the great arteries at the arterial level with particular reference to post-operative left ventricular function. Coeur 1982; 8: 589-96.

19 Yacoub MH, Bernhard A, Lange $P$, et al. Clinical and haemodynamic results of the two-stage anatomic correction of simple transposition of the great arteries. Circulation 1980; 62 (suppl I): I-190-6.

20 Arensman FW, Radley-Smith R, Yacoub MH, et al. Catheter evaluation of left ventricular shape and function one or more years after anatomic correction of transposition of the great arteries. Am $\mathcal{F}$ Cardiol 1983; 52: 1079-83.

21 Borow KM, Arensman FW, Webb C, Radley-Smith R, Yacoub MH. Assessment of left ventricular contractile state after anatomic correction of transposition of the great arteries. Circulation 1983; 69: 106-12.

22 Duncan WJ, Freedom RM, Rowe RD, Olley PM, Williams WG, Trusler GA. Echocardiographic features before and after the Jatene procedure (anatomic correction) for transposition of the great vessels. Am Heart $\mathcal{F} 1981$; 102: 227-32.

23 Silverman NH, Payot M, Stanger P, Rudolph AM. The echocardiographic profile of patients after Mustard's operation. Circulation 1978; 58: 1083-93.

24 Burggraf GW, Craige E. Echocardiographic studies of left ventricular wall motion and dimensions after valvular heart surgery. Am $\mathcal{F}$ Cardiol 1975; 35: 473-80. 